\title{
The influence of polyvalent metal cations on the corrosion rate of molybdenum in molten glass
}

\author{
Ine Vanmoortel ${ }^{\mathrm{a}}$, Joost De Strycker ${ }^{\mathrm{b}}$, Eduard Temmerman ${ }^{\mathrm{a}}$, Annemie Adriaens ${ }^{\mathrm{a}, *}$ \\ a Department of Analytical Chemistry, Ghent University, Krijgslaan 281-S12, B-9000 Ghent, Belgium \\ ${ }^{\mathrm{b}}$ Arcelor Innovation - R\&D, OCAS N.V., J. Kennedylaan 3, B-9060 Zelzate, Belgium
}

Received 14 June 2006; received in revised form 12 February 2007

Available online 5 April 2007

\begin{abstract}
The corrosion behavior of molybdenum in a silicate melt has been studied using electrochemical techniques. The aim was to examine whether or not polyvalent metal ions such as iron $\left(\mathrm{Fe}^{3+}\right)$, nickel $\left(\mathrm{Ni}^{2+}\right)$ and cobalt $\left(\mathrm{Co}^{2+}\right)$ are able to influence the corrosion behavior of molybdenum and, if so, to which extent. In addition the impact of the temperature of the melt on the corrosion rate has been addressed. (C) 2007 Elsevier B.V. All rights reserved.
\end{abstract}

PACS: 82.45.-h; 82.45.Bb; 82.45.Fk; 81.05.Kf

Keywords: Corrosion; Glass formation

\section{Introduction}

The electric melting of glass has become a method with increasing importance in the glass and enamel production industry as a result of various technical and ecological advantages [1-4]. The procedure involves bringing heat into the glass melt by means of the Joule effect using an ac current through electrodes.

Today, molybdenum is commonly used as electrode material for glass melting. It has a high melting point, a high thermal and electrical conductivity and it is mechanical stable up to temperatures of $1600^{\circ} \mathrm{C}$. However, the most important problem associated with the electrical glass melting and the use of molybdenum electrodes is the significant corrosion of the electrode material [5-7]. This corrosion process causes the molybdenum electrodes to be damaged.

One of the more important factors which influences the corrosion of molybdenum electrodes is the chemical com-

\footnotetext{
* Corresponding author.

E-mail address: annemie.adriaens@ugent.be (A. Adriaens).
}

position of the melt. Since molybdenum is one of the less noble metals, it will be oxidized in the presence of nearly all other polyvalent ions in the melts. The temperature and viscosity of the melt and the density and frequency of the heating current are other factors that may well influence the corrosion.

Several studies on the corrosion behavior of molybdenum electrodes in glass melts have been published [2-17]. Two categories can be distinguished here: studies which investigate the corrosion reaction and the influence of different parameters on it [2-9] and studies concerning the corrosion protection [9-17]. The study of the corrosion reaction has already been approached through a great number of methods, including electrochemical techniques $[2-5,9,10,16]$. These electrochemical methods are quite suitable for this purpose because of the electrochemical nature of the corrosion process and the good conductivity of molten glass.

In this study the influence of iron, nickel and cobalt on the corrosion of molybdenum in a molten enamel is investigated using electrochemical techniques. The aim is to examine whether or not these polyvalent metal ions are able to influence the corrosion behavior of molybdenum 
and, if so, to which extent. In addition, the influence of the temperature of the melt on the corrosion rate is addressed.

\section{Experimental procedures}

In order to select a relatively simple and representative primary glass, a large number of compositions were compared. A composition, containing no electroactive species, but with a satisfactory electrical conductivity was selected. The chemical composition of this basic melt is given in Table 1. All reagents used to prepare the melts were of analytical grade.

A preliminary study existed in determining the standard reduction potentials of the redox couples, $\mathrm{Fe}^{3+} / \mathrm{Fe}^{2+}, \mathrm{Ni}^{2+} /$ $\mathrm{Ni}, \mathrm{Co}^{2+} / \mathrm{Co}^{+}, \mathrm{Mo}^{(x+n)} / \mathrm{Mo}^{x+} / \mathrm{Mo}$, using square wave voltammetry. For each redox couple $1 \mathrm{wt} \%$ of the oxide of the metal under investigation (i.e. $\mathrm{Fe}_{2} \mathrm{O}_{3}, \mathrm{Ni}_{2} \mathrm{O}_{3}, \mathrm{Co}_{3} \mathrm{O}_{4}$ or $\mathrm{MoO}_{3}$ ) was added to the basic glass melt and the current-potential curves were acquired at a platinum electrode with a frequency between 200 and $10 \mathrm{~Hz}$. The choice of using these oxides as sources for the various redox couples is based on previous research results [18-20]. All reagents used were of analytical grade.

The extent of the impact of their presence was performed by adding different concentrations of the various oxides to the basic melt. For each melt composition three types of electrochemical experiments were carried out. First the corrosion potential $\left(E_{\text {corr }}\right)$ was measured as a function of time. Even though this parameter will not give direct information with regard to the corrosion rate or mechanism, it provides useful information with regard to the surface reactivity. Once a stable potential was reached electrochemical impedance measurements were performed to obtain information on the electrolyte resistance. Finally, linear potential sweep voltammograms were recorded in a small potential region around $E_{\text {corr }}$ to obtain the polarization resistance, which is directly related to the corrosion rate. In addition mass loss experiments were performed, providing additional information about the corrosion behavior.

The influence of the temperature on the corrosion rate was determined by measuring the polarization resistance in a temperature range of $1473-1173 \mathrm{~K}$ using one melt of each metal.

Table 1

Chemical composition of the melt (= basic glass melt)

\begin{tabular}{lc}
\hline Oxide & Content in $w \mathrm{t} \%$ \\
\hline $\mathrm{SiO}_{2}$ & $62.8 \pm 0.3$ \\
$\mathrm{Na}_{2} \mathrm{O}$ & $18.2 \pm 0.2$ \\
$\mathrm{CaO}$ & $7.8 \pm 0.1$ \\
$\mathrm{~B}_{2} \mathrm{O}_{3}$ & $4.9 \pm 0.1$ \\
$\mathrm{MgO}$ & $3.5 \pm 0.1$ \\
$\mathrm{Al}_{2} \mathrm{O}_{3}$ & $1.8 \pm 0.1$ \\
$\mathrm{~K}_{2} \mathrm{O}$ & $0.8 \pm 0.1$ \\
\hline
\end{tabular}

\subsection{Electrochemical experiments}

A vertical tube furnace was modified to be powered with dc current in order to avoid the effect of an ac current on the electrochemical experiments, as previously described by Rüssel et al. [21,22]. A water cooled flange of stainless steel was placed on top of the furnace. In this flange the reference and counter electrode are attached.

The reference electrode is a rod of yttria stabilized zirconia, the upper part of which is cemented into an alumina tube with a ceramic mortar. Inside this tube a pressure contact with the zirconia is made with the aid of a platinum wire and as reference gas air is blown through the tube [23]. All potentials mentioned in this paper refer to this reference. The counter electrode is a platinum plate with a surface area of approximately $3 \mathrm{~cm}^{2}$.

The working electrode is an inlaid disc electrode. For the preliminary study a platinum electrode is used, whereas for the corrosion study it is a molybdenum electrode. These inlaid disc electrodes are constructed according to a paper by De Strycker et al. [24]: a platinum rod (3 $\mathrm{mm}$ diameter; $99.95 \%$ pure) respectively a molybdenum rod $(5 \mathrm{~mm}$ diameter; $99.98 \%$ pure) is fixed in an alumina tube ( $8 \mathrm{~mm}$ inner diameter; $99.7 \%$ pure) with a ceramic binder in such a way that only the cross section of the rod is used as electrode surface. A fresh surface of the working electrode is obtained by polishing with SiC-emery paper, type 1200 grit for $30 \mathrm{~s}$. To smoothen this relatively rough surface it was further polished on a polishing cloth with alumina powder of successively 1.0 and $0.05 \mu \mathrm{m}$ particle size for respectively, 5 and $10 \mathrm{~min}$. The polishing sequence was carried out on a disk polishing machine. To remove any adsorbed alumina particles an ultrasonic cleaning step was introduced. Contact is made with a platinum wire on top. The alumina tube was purged with pure nitrogen to avoid contact between the molybdenum and the air.

The electrochemical cell, which is an alumina oxide crucible, filled with the melt was lifted in the furnace with the aid of an alumina tube placed on two lab jacks. This system allows one to control the position in the furnace very precisely. Checking of the contact between electrodes and the melt was carried out through electrical conductivity measurements. After dipping in the reference and counter electrode the furnace was flushed with pure nitrogen and the working electrode was immersed and attached in the water cooled flange. Subsequently the atmosphere is changed by blowing air in the furnace. The operating temperature for all tests (except for the temperature dependence tests) was $1473 \mathrm{~K}$.

For all electrochemical experiments a PC controlled potentiostat and software package type GPES 4.5 (Autolab PGSTAT20 from ECO Chemie) was used. The potentiostat was extended with a frequency response analyzer module to perform EIS (FRA 4.5). Impedance measurements were performed between 100 and $100 \mathrm{mHz}$. The resistance ranged between 10 and $1 \mathrm{kHz}$, depending on the measurement performed. 


\subsection{Mass loss experiments}

In these experiments rods $(30 \mathrm{~mm}$ length, $5 \mathrm{~mm}$ diameter) of molybdenum were positioned in an alumina crucible. The crucible was filled with the basic melt and placed in a chamber furnace at $1473 \mathrm{~K}$ for 10 days. After 10 days the entire content of the crucible was poured in water at room temperature. Due to the fast cooling and the difference in shrinkage coefficient between the glass and molybdenum, the glass in general does not adhere to the metal surface. To remove small, adhering pieces of glass, the rods were cleaned with hydrofluoric acid (Vel 48-51\%). Hence an accurate determination of the mass loss is possible.

\section{Results}

\subsection{Preliminary study}

The spontaneity of a redox reaction in a particular solvent, be it in an aqueous solution or in a glass-forming melt, can be predicted by determining the reduction potentials of the redox couples. In this study the reduction potentials of $\mathrm{Fe}^{3+} / \mathrm{Fe}^{2+}, \mathrm{Ni}^{2+} / \mathrm{Ni}, \mathrm{Co}^{2+} / \mathrm{Co}^{+}, \mathrm{Mo}^{(x+n)} / \mathrm{Mo}^{x+} / \mathrm{Mo}$ were determined using square-wave voltammetry. The latter technique was used as it has previously shown to obtain a high sensitivity under the conditions measured [18]. Fig. 1 shows the square wave voltammetric curves. The peak potentials in this plot are equal to the reduction potential of the attributed redox pair. It is generally accepted that the potential of the reference electrode used in this study would be zero if the reference gas was pure $\mathrm{O}_{2}$. In other words the $\mathrm{ZrO}_{2} / \mathrm{Pt} /$ air electrode fulfils the same function as the Normal Hydrogen Electrode in aqueous solutions $[25,26]$. The latter implies the standard potentials of the redox pairs can be obtained by correcting the peak potentials for the use of air instead of pure $\mathrm{O}_{2}$. Fig. 2 gives the order of the redox couples in the investigated glass at $1473 \mathrm{~K}$ arranged by their standard reduction potential.

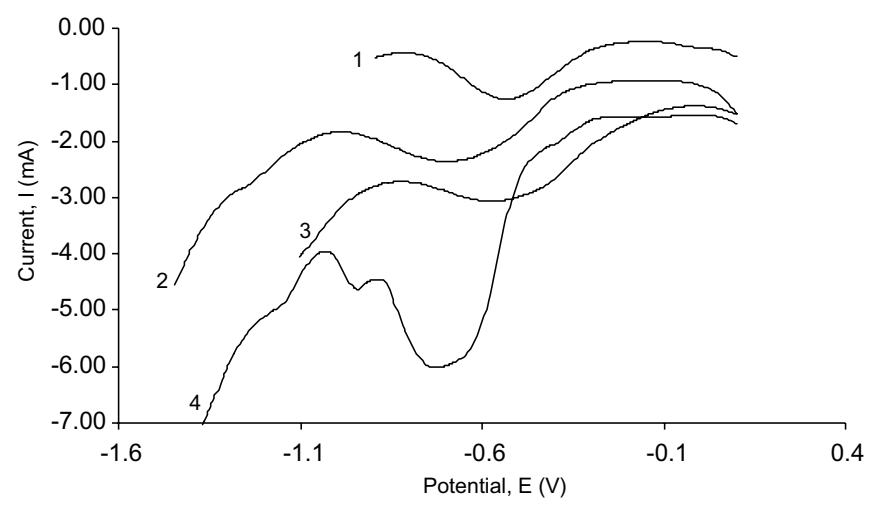

Fig. 1. Square wave voltammetric curves recorded at a platinum electrode in the basic glass melt modified with different oxides. (1) $1 \mathrm{wt} \% \mathrm{Ni}_{2} \mathrm{O}_{3}$, $f=10 \mathrm{~Hz}$, (2) $1 \mathrm{wt} \% \mathrm{Co}_{3} \mathrm{O}_{4}, f=50 \mathrm{~Hz}$, (3) $1 \mathrm{wt} \% \mathrm{Fe}_{2} \mathrm{O}_{3}, f=50 \mathrm{~Hz}$, (4) $1 \mathrm{wt} \% \mathrm{MoO}_{3}, f=50 \mathrm{~Hz}$. Square wave amplitude $=50 \mathrm{mV}$; temperature $=1473 \mathrm{~K}$. The reference electrode is a rod of yttria stabilized zirconia.

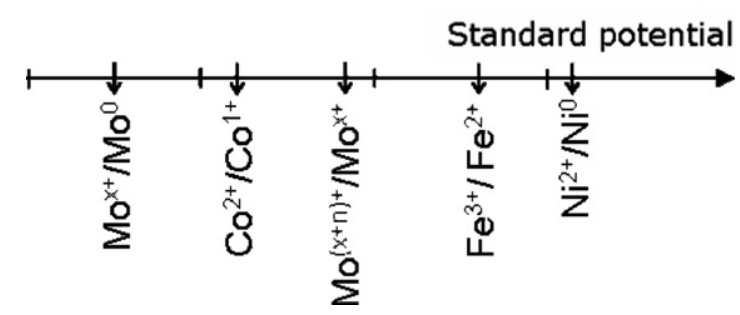

Fig. 2. Redox reactions arranged by their standard potential at $1473 \mathrm{~K}$ in the basic glass melt. Absolute values are not given as they depend on the composition of the melt they have been measured in.

\subsection{Corrosion study}

The surface reactivity of molybdenum was studied by determining the corrosion potential of the metal when immersed in the glass melt containing one of the oxides and this under various concentrations. The time required to reach a non-fluctuating value depends on the composition of the melt and takes between 2 and $16 \mathrm{~h}$. The stable $E_{\text {corr }}$ values for the various melt compositions are given in Table 2. Although the corrosion potentials are all situated within a range of $150 \mathrm{mV}$, in each series of measurements a clear tendency can be observed. With the exception of $2.5 \mathrm{wt} \% \quad \mathrm{Co}_{3} \mathrm{O}_{4}$, the corrosion potential increases (becomes less negative) with increasing cation concentration.

Linear potential sweep voltammetry was used to determine the polarization resistance. The latter is commonly used for corrosion rate monitoring and is defined by the slope of the (linear) potential sweep voltammogram at $E_{\text {corr }}$.

$R_{\mathrm{p}}=\left(\frac{\Delta E}{\Delta I}\right)_{E_{\text {corr }}}$

However, by using linear potential sweep voltammetry, the data may suffer from the contribution of capacitive currents and Ohmic drop effects. The capacitive currents are proportional to the potential sweep rate. The latter implies that if the slope of the curves is not affected by the scan

Table 2

Average stable $E_{\text {corr }}$ values

\begin{tabular}{lcl}
\hline Compound & Quantity $(\mathrm{wt} \%)$ & $E_{\text {corr }}(\mathrm{mV})$ \\
\hline $\mathrm{Fe}_{2} \mathrm{O}_{3}$ & 2.5 & $-808 \pm 21$ \\
& 5.0 & $-790 \pm 6$ \\
& 7.5 & $-733 \pm 4$ \\
& 10.0 & $-703 \pm 2$ \\
$\mathrm{Ni}_{2} \mathrm{O}_{3}$ & 0.5 & $-825 \pm 17$ \\
& 1.0 & $-818 \pm 10$ \\
& 1.5 & $-809 \pm 5$ \\
& 2.5 & $-763 \pm 6$ \\
$\mathrm{Co}_{3} \mathrm{O}_{4}$ & 0.5 & $-826 \pm 23$ \\
& 1.0 & $-821 \pm 17$ \\
& 1.5 & $-810 \pm 14$ \\
& 2.5 & $-819 \pm 4$ \\
\hline
\end{tabular}




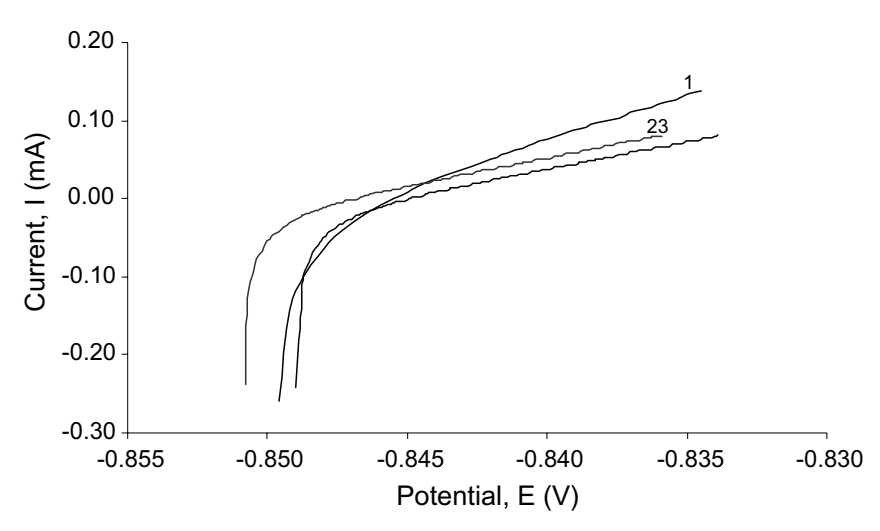

Fig. 3. Linear sweep voltammetric curves recorded with different potential sweep rates at a molybdenum electrode in the basic glass melt at $1473 \mathrm{~K}$. Sweep rates are (1) 0.2 , (2) 0.05 , (3) $0.01 \mathrm{mV} \mathrm{s}^{-1}$. The reference electrode is a rod of yttria stabilized zirconia.

rate, there is no significant contribution from capacitive currents. Fig. 3 shows three current-potential curves obtained by linear sweep voltammetry in the basic glass melt. The curves were recorded at three different potential sweep rates $\left(0.2 \mathrm{mV} \mathrm{s}^{-1}, 0.05 \mathrm{mV} \mathrm{s}^{-1}, 0.01 \mathrm{mV} \mathrm{s}^{-1}\right)$. The highest scan rate gives rise to a steeper slope, the other curves are parallel, indicating there is not any significant influence of capacitive currents. In order to comply with this and at the same time keep the duration of the measurements to a minimum, data were acquired with a scan rate of $0.05 \mathrm{mV} \mathrm{s}^{-1}$. The Ohmic resistance on the other hand, was determined using electrochemical impedance measurements and is of the same order as $R_{\mathrm{p}}$ (i.e. ca $2 \Omega \mathrm{cm}^{2}$ ). The latter implies the need for taking the Ohmic resistance into account when determining the polarization resistance.

The inverse $R_{\mathrm{p}}$ values of molybdenum as a function of the various oxide concentrations are presented in Fig. 4. The values are averaged over at least 5 measurements performed between 24 and $28 \mathrm{~h}$ after immersion of the elec-

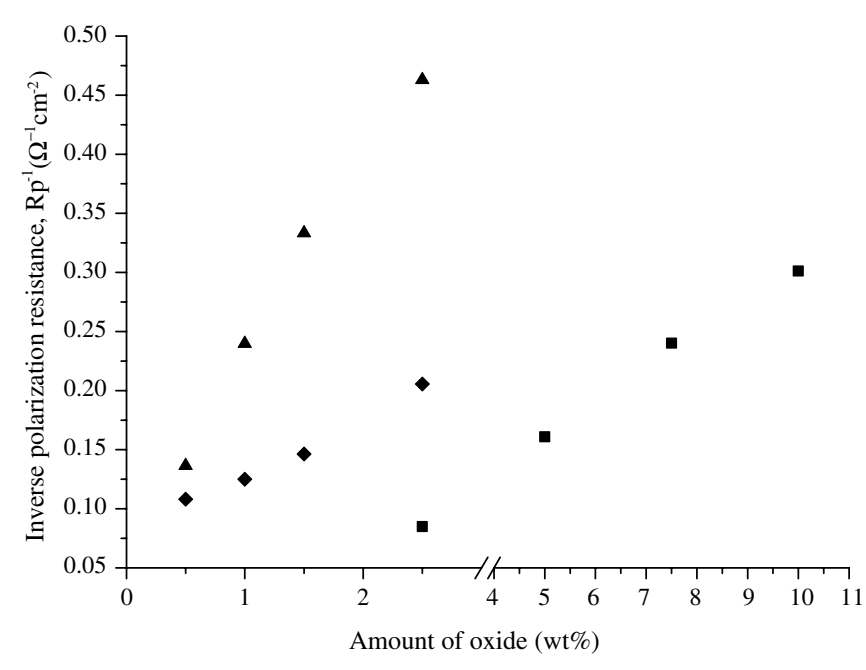

Fig. 4. Inverse of the polarization resistance of molybdenum at $1473 \mathrm{~K}$ plotted versus $(\boldsymbol{\Delta}) \mathrm{Fe}_{2} \mathrm{O}_{3},(\diamond) \mathrm{Ni}_{2} \mathrm{O}_{3}$ and $(\boldsymbol{\square}) \mathrm{Co}_{3} \mathrm{O}_{4}$ concentration in the glass melt.
Table 3

Mass loss data of molybdenum in various glass melts

\begin{tabular}{lcc}
\hline Compound & Quantity $\left(\mathrm{wt}^{\circ} \%\right)$ & $\Delta m\left(\mathrm{mg} \mathrm{cm}^{-2}\right)$ \\
\hline $\mathrm{Fe}_{2} \mathrm{O}_{3}$ & 2.5 & 15.0 \\
& 5.0 & 59.5 \\
& 7.5 & 237.1 \\
& 10.0 & 330.9 \\
$\mathrm{Ni}_{2} \mathrm{O}_{3}$ & 0.5 & 9.5 \\
& 1.0 & 29.8 \\
& 1.5 & 91.3 \\
& 2.5 & 196.1 \\
$\mathrm{Co}_{3} \mathrm{O}_{4}$ & 0.5 & 3.5 \\
& 1.0 & 10.0 \\
& 1.5 & 18.8 \\
& 2.5 & 39.1 \\
\hline
\end{tabular}

trode into the glass melt. In accordance with the practical experience, the inverted polarization resistance increases with increasing oxide concentrations or in other words the corrosion rate is augmented at a higher $\mathrm{Fe}_{2} \mathrm{O}_{3}, \mathrm{Ni}_{2} \mathrm{O}_{3}$ or $\mathrm{Co}_{3} \mathrm{O}_{4}$ concentration. The results of mass loss experiments performed in glass melts with the same composition are given in Table 3 . They show a clear increase in mass loss of the molybdenum rod with higher concentrations of the metal cations.

\subsection{Influence of temperature}

In order to obtain information about the influence of the temperature on the corrosion rate, the polarization resistance was determined for a temperature range from $1173 \mathrm{~K}$ to $1473 \mathrm{~K}$ in the basic melt and three melts were modified with the lowest $\mathrm{Fe}_{2} \mathrm{O}_{3}, \mathrm{Ni}_{2} \mathrm{O}_{3}$ and $\mathrm{Co}_{3} \mathrm{O}_{4}$ concentration. The results are shown in Fig. 5 in the form of Arrhenius plots.

\section{Discussion}

The ranking of the standard reduction potentials for the various metal ions, presented in Fig. 2, confirms that molybdenum has the most negative standard potential. The latter indicates that iron, nickel and cobalt can act as an oxidizing agent (electron acceptor) with respect to molybdenum.

Their actual involvement is demonstrated by the shift of the $E_{\text {corr }}$ data to less negative values as a function of the oxide concentration (Table 2). This trend can be explained by a theoretical current-potential curve of a corrosion system (Fig. 6). In case iron, nickel and cobalt act as oxidizing agent (or electron acceptor) in the corrosion reaction of molybdenum, an increasing concentration of these metal ions results in a raised cathodic current, depicted as the dashed curve in Fig. 6. The latter implies that the $E_{\text {corr }}$ value $\left(i_{\mathrm{M}}=-i_{\mathrm{EA}}\right)$ shifts to a more positive value (or to the right on the figure).

The polarization resistance values (Fig. 4) as well as the results of mass loss experiments given, in Table 3, show 


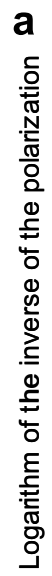
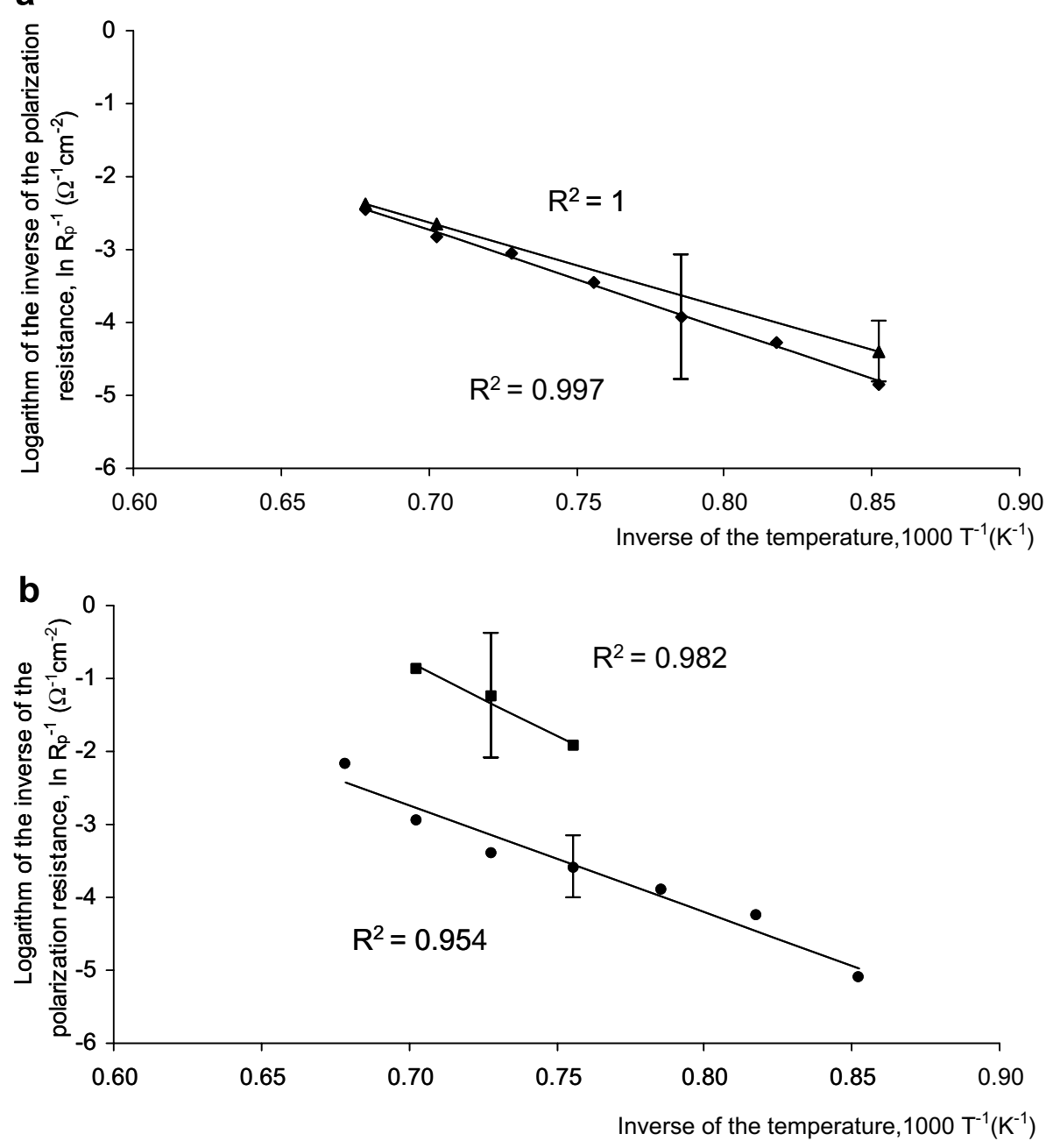

Fig. 5. Arrhenius plot of the inverse of the polarization resistance of molybdenum at $1473 \mathrm{~K}$. (a) ( $(\mathbf{)})$ in the basic glass melt, $(\boldsymbol{\Delta})$ in the basic glass melt modified with $2.5 \mathrm{wt} \% \mathrm{Fe}_{2} \mathrm{O}_{3}$. (b) (ם) in the basic glass melt modified with $1.0 \mathrm{wt} \% \mathrm{Ni}_{2} \mathrm{O}_{3},(\mathbf{O})$ in basic glass melt modified with $1.0 \mathrm{wt} \% \mathrm{Co}_{3} \mathrm{O}_{4}$. Each set of data has been fitted by the method of least squares.

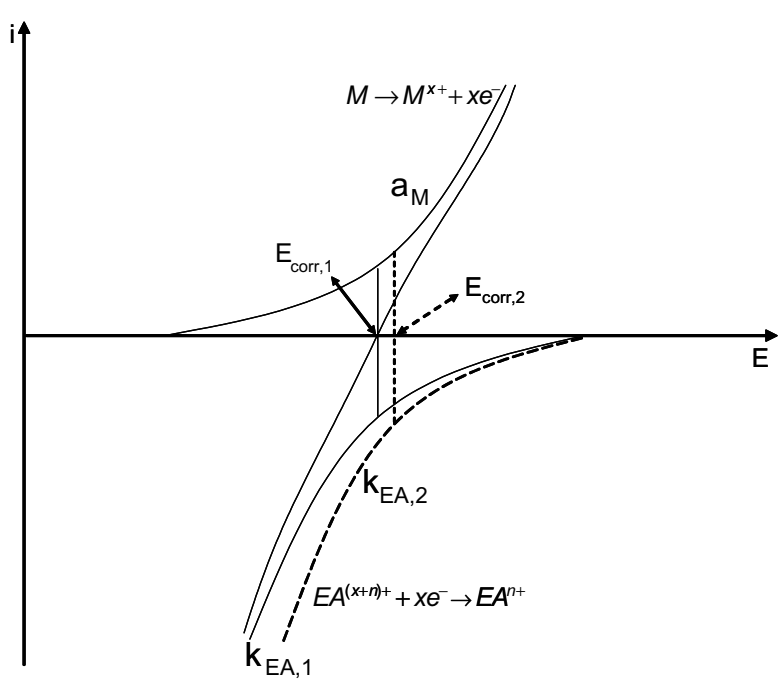

Fig. 6. Schematic of a current-potential curve of a corroding system. $a_{\mathrm{M}}$ : anodic curve of the metal $(\mathrm{M}), k_{\mathrm{EA}, 1}$ and $k_{\mathrm{EA}, 2}$ : cathodic curves for different the electron acceptor (EA) concentrations. $k_{\mathrm{EA}, 1}$ lowest concentration, $k_{\mathrm{EA}, 2}$ highest concentration. that the corrosion rate of molybdenum increases with higher $\mathrm{Fe}_{2} \mathrm{O}_{3}, \mathrm{Ni}_{2} \mathrm{O}_{3}$ or $\mathrm{Co}_{3} \mathrm{O}_{4}$ concentrations. The mass loss results, moreover, show nickel to be the most aggressive metal ion and iron the least aggressive metal ion.

In spite of the fact that the polarization resistance is already a relative measure for the corrosion rate and $t$, the real reaction rate $\left(I_{\text {corr }}\right)$ requires the knowledge of the Stern-Geary constant. This relationship is known as the Stern-Geary equation:

$I_{\text {corr }}=\frac{B}{R_{\mathrm{p}}} \quad$ with $\quad B=\frac{\beta_{\mathrm{a}} \cdot \beta_{\mathrm{c}}}{2.303\left(\beta_{\mathrm{a}}+\beta_{\mathrm{c}}\right)}$,

where $R_{\mathrm{p}}$ is the polarization resistance, $B$ the Stern-Geary constant $\beta_{\mathrm{a}}$ and $\beta_{\mathrm{c}}$ the anodic and cathodic Tafel slopes. In Tafel plots the current is plotted in a logarithmic way versus the potential.

Fig. 7 shows a current-potential curve obtained at a molybdenum electrode in the basic glass melt. This Tafel representation, however, does not show a decade of linearity necessary to determine the Tafel slopes. The latter can 


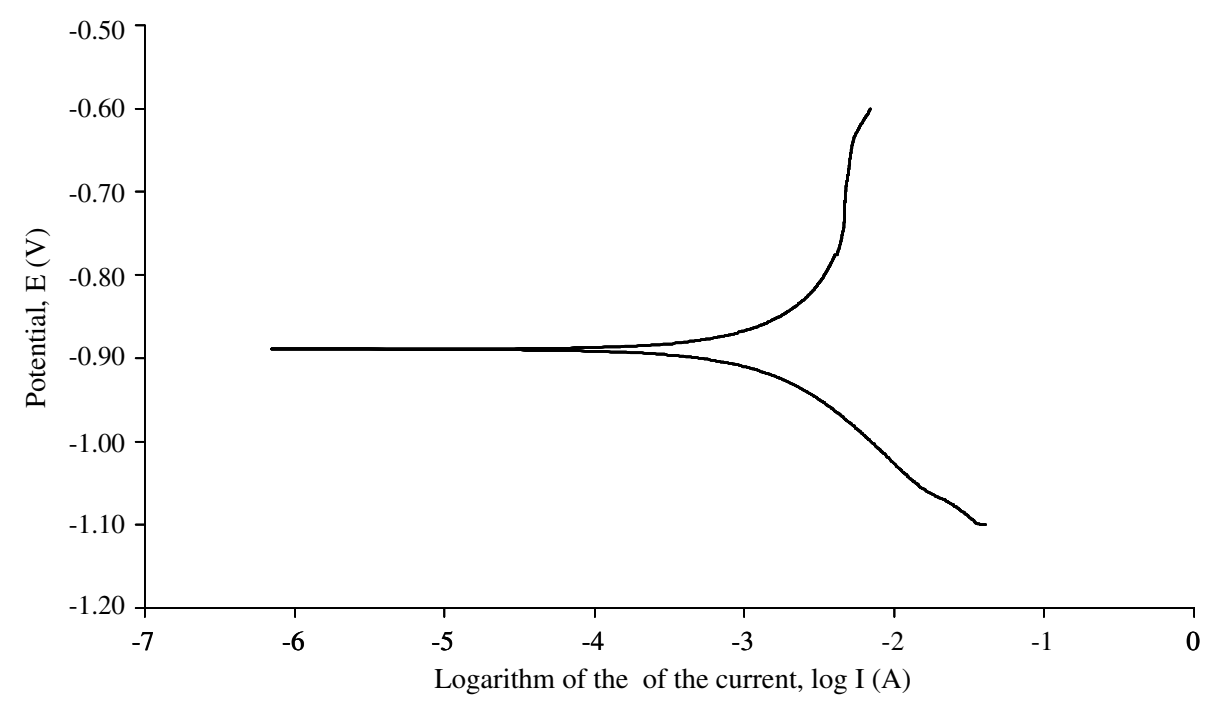

Fig. 7. Tafel representation of a current-potential curve recorded at a molybdenum electrode in the basic glass melt at $1473 \mathrm{~K}$. The reference electrode is a rod of yttria stabilized zirconia.

be explained by the high temperature of the melt. Tafel slopes are defined according to the following equation:

$\beta_{a}=\frac{2.3 R T}{F \alpha_{\mathrm{a}}} \quad \beta_{\mathrm{c}}=\frac{2.3 R T}{F \alpha_{\mathrm{c}}}$,

where $\beta_{\mathrm{a}}$ and $\beta_{\mathrm{c}}$ are the anodic and respectively cathodic Tafel slopes, $R$ the gas constant $\left(8.314 \mathrm{~J} \mathrm{~mol}^{-1} \mathrm{~K}^{-1}\right), T$ the temperature in $\mathrm{K}(1473 \mathrm{~K}), \alpha_{\mathrm{a}}$ and $\alpha_{\mathrm{c}}$ the anodic and respectively cathodic transfer coefficient and $F$ the Faraday constant $\left(96485 \mathrm{C} \mathrm{mol}^{-1}\right)$. With the exception of the transfer coefficients $\alpha_{\mathrm{a}}$ and $\alpha_{\mathrm{c}}$ all factors are known. For a one electron-step the transfer coefficients vary between 0 and 1. Assuming these values equal to 0.5 leads to $\beta=$ $583 \mathrm{mV} /$ decade. The latter implies that the linearity of at least one decade can occur when no other reaction takes place in that interval. This condition is rarely fulfilled in glass melts.

ASTM procedures to determine the corrosion rate describe several possibilities to obtain the Stern-Geary constant in a non-electrochemical way by for example coupling of mass loss and polarization resistance measurements [27]. A combination of Faraday's law (4) and Eq. (2) predicts a linear relationship between the mass loss per time unit and the inverted polarization resistance (5).

$i_{\text {corr }} t=n F \frac{\Delta m}{M_{\mathrm{R}}}$

$\Delta m_{\text {time }}=\frac{M_{\mathrm{R}} B}{n F} \cdot R_{\mathrm{P}}^{-1}=$ constant $\cdot R_{\mathrm{P}}^{-1}$,

where $\Delta m$ and $\Delta m_{\text {time }}$ are the mass loss in $\mathrm{g} \mathrm{cm}^{-2}$ and respectively mass loss per time unit in $\mathrm{g} \mathrm{s}^{-1} \mathrm{~cm}^{-2}, M_{\mathrm{R}}$ the molecular weight in $\mathrm{g} \mathrm{mol}^{-1}, t$ the time in $\mathrm{s}, n$ the number of transferred electrons, $F$ the Faraday constant $\left(96485 \mathrm{C} \mathrm{mol}^{-1}\right), R_{\mathrm{p}}$ the polarization resistance in $\Omega \mathrm{cm}^{2}$ and $i_{\text {corr }}$ the corrosion current in $\mathrm{A} \mathrm{cm}^{-2}$. The mass loss per time $\left(\Delta m\right.$ in $\left.\mathrm{mg} \mathrm{s}^{-1} \mathrm{~cm}^{-2}\right)$ unit as a function of the inverted polarization resistance $\left(R_{\mathrm{p}}^{-1}\right.$ in $\left.\Omega^{-1} \mathrm{~cm}^{-2}\right)$ when $\mathrm{Fe}_{2} \mathrm{O}_{3}$ is present in the melt is plotted in Fig. 8. This curve

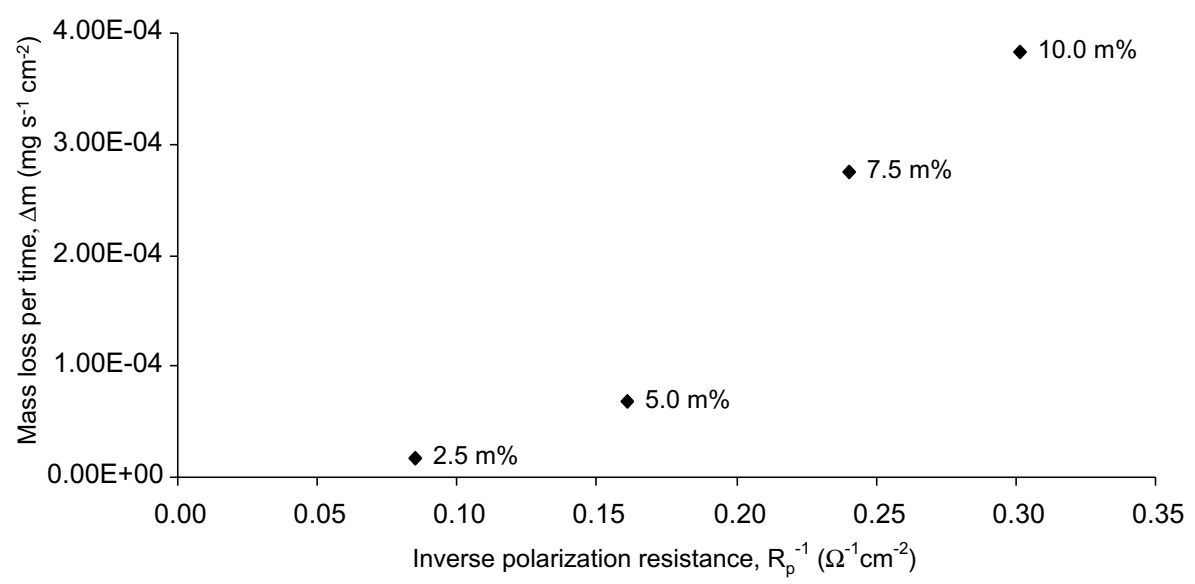

Fig. 8. The mass loss per time $\left(\Delta m\right.$ in $\left.\mathrm{mg} \mathrm{s}^{-1} \mathrm{~cm}^{-2}\right)$ unit as a function of the inverse of the polarization resistance $\left(R_{\mathrm{p}}^{-1}\right.$ in $\left.\Omega^{-1} \mathrm{~cm}^{-2}\right)$ of a molybdenum electrode in glass melts with varying $\mathrm{Fe}_{2} \mathrm{O}_{3}$ concentrations. 
does not show the expected linear relationship. Similar results were obtained for $\mathrm{Ni}_{2} \mathrm{O}_{3}$ en $\mathrm{Co}_{3} \mathrm{O}_{4}$. An explanation for this discrepancy could be found in the different duration of the experiments. On the one hand, the mass losses are time averaged results of the corrosion reaction that took place during ten days. On the other hand, the inverted polarization resistance is a measure for the corrosion rate at a given moment. Considering the fact that the rate of corrosion processes does not proceed linearly as a function of time these results could be different.

The above-mentioned results have shown that it is not possible to obtain the Stern-Geary constant in the glass melt environment. For this reason, the inverted polarization resistance is further used to investigate the influence of the temperature on the corrosion rate of molybdenum in the basic melt and three melts modified with the lowest $\mathrm{Fe}_{2} \mathrm{O}_{3}, \mathrm{Ni}_{2} \mathrm{O}_{3}$ and $\mathrm{Co}_{3} \mathrm{O}_{4}$ concentration. The Arrhenius plots of the inverted polarization resistances shown in Fig. 5 reveal a good linear fit for each melt composition. The straight line indicates that the same corrosion mechanism is valid over a wide temperature range. Moreover the Arrhenius-type diagrams reveal an activation energy of $113,97,166$ and $121 \mathrm{~kJ} \mathrm{~mol}^{-1}$ for the corrosion reaction of molybdenum respectively in the basic melt and melts modified with $\mathrm{Fe}_{2} \mathrm{O}_{3}, \mathrm{Ni}_{2} \mathrm{O}_{3}$, and $\mathrm{Co}_{3} \mathrm{O}_{4}$.

\section{Conclusions}

This study focused on the influence of polyvalent metal ions of iron, nickel and cobalt on the corrosion behavior of molybdenum rods in glass melts. Using corrosion potential measurements, it was possible to identify iron, nickel and cobalt as reduction partners in the corrosion of molybdenum. In addition, nickel could be classified as the most aggressive ion, and iron the least aggressive ion.

The polarization resistance method was used to investigate the corrosion rate and the effect of the temperature on it. The results showed an increased corrosion rate with higher concentration of iron, nickel and cobalt ions. The temperature dependence study showed a constant corrosion mechanism across the temperature range of 1173$1473 \mathrm{~K}$ and allowed us to determine the activation energies of the corrosion processes.

In spite of the fact that the polarization resistance is already a relative measure for the corrosion rate, the real reaction rate requires the knowledge of the Stern-Geary constant or Tafel slopes. Different methods to obtain the Stern-Geary constant were evaluated but none of them were satisfactory to retrieve the value of the constant for molybdenum in molten glass. For this reason, the inverted polarization resistance remains to be used as a measure for the corrosion rate despite its limitations.

\section{Acknowledgements}

The authors like to thank K. Lips and K. Simoens (PEMCO Brugge bvba, Department Technical Service and Development) for their collaboration.

\section{References}

[1] J. Staněk, Electric Melting of Glass, Elsevier, Amsterdam - Oxford New-York, 1977.

[2] T. Rudolph, G.B. Balazs, C. Rüssel, G. Tomandl, Glastech. Ber. 61 (7) (1988) 177.

[3] G.B. Balazs, C. Rüssel, J. Non-Cryst. Solids 105 (1988) 1.

[4] S. Holzwarth, C. Rüssel, G. Tomandl, Glastech. Ber. 64 (8) (1991) 195.

[5] Y. Miura, K. Takahashi, J. Non-Cryst. Solids $38 \& 39$ (1980) 347.

[6] J. Matěj, Š. Freivolt, V. Hulinský, Ceramics - Silikáty 40 (1996) 1.

[7] J. Matěj, V. Hulinský, Ceramics - Silikáty 42 (3) (1998) 132.

[8] N.I. Min'ko, N.F. Zhernovaya, O.I. Tkachenko, V.Yu. Krasavin, Z.p. Baskova, Glass Ceram. 57 (9/10) (2000) 333.

[9] S.K. Sundaram, R.F. Speyer, J. Am. Ceram. Soc. 79 (7) (1996) 1851.

[10] C. Rüssel, Glastech. Ber. 64 (5) (1991) 123.

[11] B. Fleischmann, K.W. Mergler, H. Barklage-Hilgefort, Glastech. Ber. 66 (4) (1993) 85.

[12] J. Matěj, Glastech. Ber. 61 (1) (1988) 1.

[13] J. Matěj, Glastech. Ber. 63 (8) (1990) 8.

[14] J. Matěj, V. Bernard, Glastech. Ber. 66 (12) (1993) 1.

[15] C. Rüssel, A. Kampfer, Glastech. Ber. Glass Sci. Technol. 71 (1) (1998) 6.

[16] C. Rüssel, A. Kampfer, Glastech. Ber. Glass Sci. Technol. 71 (1) (1998) 35

[17] B. Fleischmann, K.W. Mergler, Glastech. Ber. Glass Sci. Technol. 71 (5) (1998) 103.

[18] J. De Strycker, P. Westbroek, E. Temmerman, Electrochem. Commun. 4 (2002) 41.

[19] J. De Strycker, P. Westbroek, E. Temmerman, J. Non-Cryst. Solids 347 (2004) 231

[20] J. De Strycker, P. Westbroek, E. Temmerman, J. Electroanal. Chem. 565 (2004) 149.

[21] E. Freude, C. Rüssel, Glastech. Ber. 60 (1987) 202.

[22] C. Rüssel, G. Sprachmann, J. Non-Cryst. Solids 127 (1991) 197.

[23] P. Ruz, A. Lenhart, H.A. Schaeffer, Fortschr. Deutsch. Keram. Ges. 1 (1985) 138.

[24] J. De Strycker, P. Westbroek, E. Temmerman, J. Non-Cryst. Solids 289 (2001) 106.

[25] M. Medlin, K. Siemerth, H. Schreiber, J. Non-Cryst. Solids 240 (1998) 193.

[26] E. Freude, Voltammetrische Untersuchungen des Redoxverhaltens polyvalenter Ionen in Glasschmelzen, insbesondere von Technetium, PhD dissertation, Universität Erlangen, Erlangen, 1989.

[27] ASTM 102, Annual Book of ASTM Standards, section 3, vol. 03.02, 1989. 